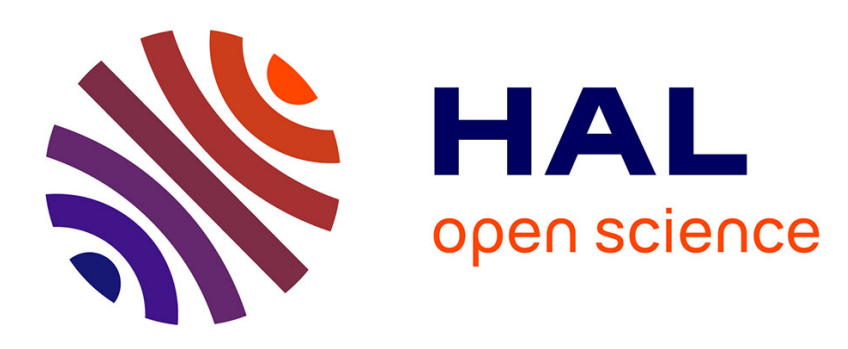

\title{
Improving Adhesion at the Alumina/Zinc Interface by Stainless Steel Buffers
}

Ha-Linh Thi Le, Jacek Goniakowski, Claudine Noguera, Alexey Koltsov, Jean-Michel Mataigne

\section{- To cite this version:}

Ha-Linh Thi Le, Jacek Goniakowski, Claudine Noguera, Alexey Koltsov, Jean-Michel Mataigne. Improving Adhesion at the Alumina/Zinc Interface by Stainless Steel Buffers. Journal of Physical Chemistry C, 2017, 121 (45), pp.25143-25151. 10.1021/acs.jpcc.7b07112 . hal-01651879

\section{HAL Id: hal-01651879 \\ https://hal.sorbonne-universite.fr/hal-01651879}

Submitted on 29 Nov 2017

HAL is a multi-disciplinary open access archive for the deposit and dissemination of scientific research documents, whether they are published or not. The documents may come from teaching and research institutions in France or abroad, or from public or private research centers.
L'archive ouverte pluridisciplinaire HAL, est destinée au dépôt et à la diffusion de documents scientifiques de niveau recherche, publiés ou non, émanant des établissements d'enseignement et de recherche français ou étrangers, des laboratoires publics ou privés. 


\title{
Improving Adhesion at the Alumina/Zinc Interface by Stainless Steel Buffers
}

\author{
Ha-Linh Thi Le, ${ }^{\dagger, t}$ Jacek Goniakowski, ${ }^{* \dagger, \dagger}$ Claudine Noguera, ${ }^{\dagger, \dagger}$ Alexey \\ Koltsov, and Jean-Michel Mataigne \\ CNRS, UMR 7588, Institut des Nanosciences de Paris, F-75005 Paris, France, Sorbonne \\ Universités, UPMC Univ Paris 06, UMR 7588, INSP, F-75005 Paris, France, and \\ ArcelorMittal Maizières Research, voie Romaine, F-57280, Maizières lès Metz, France \\ E-mail: jacek.goniakowski@insp.jussieu.fr
}

\footnotetext{
${ }^{*}$ To whom correspondence should be addressed

${ }^{\dagger}$ CNRS, UMR 7588, Institut des Nanosciences de Paris, F-75005 Paris, France

¥Sorbonne Universités, UPMC Univ Paris 06, UMR 7588, INSP, F-75005 Paris, France

^ArcelorMittal Maizières Research, voie Romaine, F-57280, Maizières lès Metz, France
} 


\begin{abstract}
The weak interaction between zinc and alumina is responsible for a poor performance of anti-corrosive galvanic zinc coatings on modern advanced high strength steels. In this context, we report a theoretical study on the effect of realistic multi-component metal buffers on the adhesion strength of a model $\alpha$-alumina(0001)|zinc interface. Relying on results of ab initio calculations on relevant individual oxide|oxide, oxide|metal, and metal|metal interfaces (separation and interface energies), we determine by Monte Carlo simulations the thermodynamically preferred sequence of components in a multicomponent buffer, as a function of buffer composition and oxygen conditions. We find that stainless steel buffers considerably enhance the overall strength of the alumina|zinc interface. Most importantly, we show that a partial oxidation of multi-component buffers, which is unavoidable under realistic conditions, does not degrade their performance. This advantageous property relies on the separation of metal and oxide components in the buffer and on the resulting suppression of weakly interacting oxide|zinc, and moderately strong alumina|metal interfaces. More generally, owing to the possibility of selective oxidation and component segregation, multi-component buffers appear as promising solutions for adhesion improvement at weakly interacting metal|oxide interfaces.
\end{abstract}

\title{
Introduction
}

Many fundamental studies have been dedicated to the understanding and optimization of the adhesion strength of transition and noble metals on oxide surfaces in view of applications in microelectronics, in engineering of thermal coatings, or for the formation of protective scales. More recently, the adhesive characteristics of metal|oxide interfaces have also been addressed in the context of galvanic zinc coatings, traditionally used for anti-corrosive protection of steels. ${ }^{1}$ Indeed, strengthening elements, such as Al, Si and Mn, which are purposely alloyed into advanced high strength steels (AHSS), ${ }^{2-5}$ oxidize selectively during the re-crystallization 
annealing of cold-rolled steel strips before galvanization. The resulting oxides segregate at the steel surface and reduce dramatically the adhesion of the anti-corrosive Zn protection. ${ }^{1,6}$ Typically, an enrichment of steel with more than 1wt.\% aluminum, may lead to the formation of a quasi-continuous alumina film at the steel surface. This replaces the conventional reactive $\mathrm{Fe} \mid \mathrm{Zn}$ interface $^{1,7}$ by a non-reactive interface between $\mathrm{Zn}$ and a wide band-gap alumina, eventually impeding zinc adhesion in the standard hot-dip galvanization process.

Despite such a strong applicative interest, the widespread use of sapphire in the growth of epitaxial zinc oxide layers, ${ }^{8}$ and a variety of studies on the interaction of metals with alumina surfaces, ${ }^{9-18}$ the adhesion of zinc has received relatively little attention in the past. ${ }^{19-24} \mathrm{In}$ a previous theoretical study, we have shown that the weak interaction of zinc with the most stable, stoichiometric $\alpha-\mathrm{Al}_{2} \mathrm{O}_{3}(0001)$ surface can only be enhanced by a net surface charge, due either to surface polarity or to an excess of surface hydroxyls. ${ }^{21,24}$ Alternatively, the introduction of a simple buffer, made of a single more strongly interacting metal such as $\mathrm{Cr}, \mathrm{Fe}$, or $\mathrm{Ni}$, at the alumina|Zn interface has been shown to enhance adhesion due to the formation of strong interfacial metal-oxygen and metal-zinc bonds. However, since buffer oxidation systematically reduces the number of such strong interfacial bonds, it produces in most cases a detrimental effect on adhesion. ${ }^{23}$

Since a (partial) buffer oxidation cannot be avoided under realistic oxidizing conditions, the goal of the present study is to investigate the performance of a multi-component buffer. By tuning its oxidation characteristics, it may be possible to accommodate an oxygen excess without degrading the overall adhesion. To this end, we focus on a typical stainless steel buffer and consider the selective oxidation of its $\mathrm{Cr}$ and/or Fe components under increasingly oxidizing conditions. The sequence of metal and oxide components within the buffer is determined by a Monte Carlo (MC) Metropolis optimization, based on interface energies of individual oxide|oxide, oxide|metal, and metal|metal interfaces obtained from dedicated Density Functional Theory (DFT) calculations. Such an approach enables to account for separation, alloying or segregation of the buffer components, to determine the thermody- 
namically favored sequence of components and interfaces within the buffer, and to identify the least adhesive interfaces.

Besides an adhesion enhancement by the metallic stainless steel buffer, we show that its partial oxidation, associated to the formation of chromium and/or iron oxides, does not degrade its performances. This is principally due to the thermodynamically favored separation of metal and oxide components in the buffer which results in the suppression of weakly interacting oxide|zinc and moderately strong alumina|metal interfaces. Besides their direct interest for the optimization of industrial buffers, our results show that an explicit account for selective oxidation and component segregation in a buffer is necessary for a correct estimation of its adhesion characteristics. Our proposed DFT-based multi-component buffer model provides a robust but simple and efficient tool to tackle this complex situation.

The paper is organized as follows. After presenting the details and settings of ab initio calculations and Monte Carlo simulations in Sec. 2, in Sec. 3 we report the values of interface and adhesion energies at all relevant individual oxide|oxide, oxide|metal, and metal|metal interfaces obtained from DFT. Sec. 4 provides and analyzes the composition profiles in metallic or partially oxidized stainless steel buffers, at thermodynamic equilibrium. It highlights the trends in mixing or segregation of their components, and the consequences for the overall interface strength. The discussion in Sec. 5 offers preliminary results to understand the consequences of interfacial diffusion and of Cr- or Ni- enrichment of the buffer.

\section{Computational methods and settings}

The complex equilibrium structure and composition of a realistic multi-component buffer $Y$, such as stainless steel, at the alumina|zinc interface are approximated by a sequence of interfaces involving its metal (Fe, Cr, Ni) and oxide $\left(\mathrm{Fe}_{2} \mathrm{O}_{3}, \mathrm{Cr}_{2} \mathrm{O}_{3}\right)$ components $\mathrm{X}_{\mathrm{i}}$ : $Y=\mathrm{X}_{1}\left|\mathrm{X}_{2}\right| \mathrm{X}_{3}|\ldots| \mathrm{X}_{\mathrm{N}}$. Assuming that the interaction between individual interfaces is negligible, the formation energy (with respect to the corresponding bulk materials) of the entire 
alumina $|Y|$ zinc system is equal to the sum of the interface energies of the successive individual interfaces: alumina $\left|\mathrm{X}_{1}, \mathrm{X}_{1}\right| \mathrm{X}_{2}, \ldots$, and $\mathrm{X}_{\mathrm{N}} \mid$ zinc, which can be obtained from dedicated small-scale $a b$ initio calculations. The global structural optimization of $Y$ is then reduced to a search for an optimal sequence of its components $\mathrm{X}_{\mathrm{i}}$ and the strength of the entire system is determined by the weakest (the least adhesive) individual $\mathrm{X}_{\mathrm{i}} \mid \mathrm{X}_{\mathrm{i}+1}$ interface.

The computational approach thus involves calculations at two different levels. First, a DFT-based method is used for a precise estimation of interface and adhesion energies associated to all relevant interfaces. Then, a Monte Carlo Metropolis optimization of the component sequence in the multi-component buffer is performed.

Ab initio calculations. All calculations on individual interfaces were performed within the DFT implemented in VASP (Vienna ab initio simulation package). ${ }^{25,26}$ The interaction of valence electrons with ionic cores was described within the projector augmented wave (PAW) method, ${ }^{27,28}$ the Kohn-Sham orbitals were developed on a plane-wave basis set with a cutoff energy of $400 \mathrm{eV}$. The dispersion-corrected GGA (optB88-vdW) ${ }^{29-31}$ exchange-correlation functional was used to improve the description of adhesion characteristics, especially at weakly interacting metal/alumina interfaces, such as between $\mathrm{Zn}$ and the stoichiometric alumina(0001) termination. ${ }^{22}$ Since it has a relatively small effect on the energetic trends, we did not employ the GGA $+\mathrm{U}$ approach to correct the electronic structure of the oxides under consideration. ${ }^{22}$ All calculations were spin-polarized and the relative stability of simple non-magnetic, ferro- and antiferro-magnetic solutions was systematically tested. The self-consistent iterative solution of the electronic Hamiltonian was converged until energy differences became smaller than $10^{-6} \mathrm{eV}$. The above settings assure a satisfactory agreement between calculated and experimental characteristics of the bulk materials as demonstrated in Figure 1, which displays the oxygen conditions under which the metals under consideration and their oxides are stable.

Figure 2 shows the models of oxide|oxide, metal|metal, and oxide|metal interfaces used 


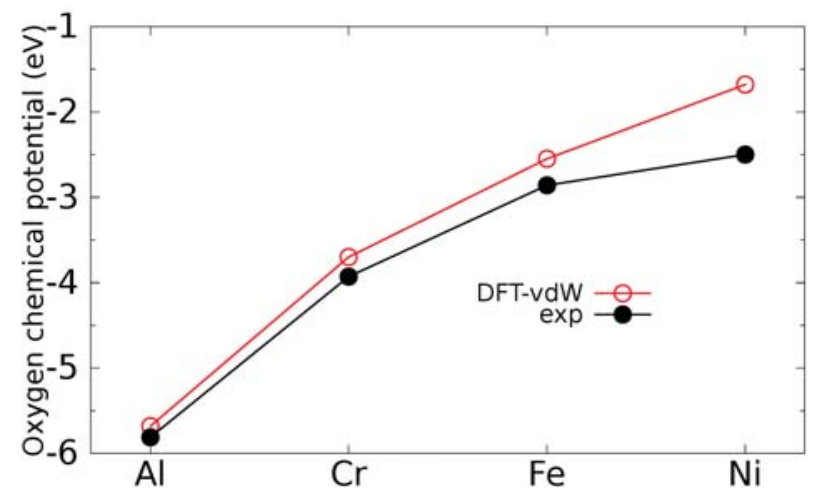

Figure 1: Critical values of oxygen chemical potential above which oxidation of metals is thermodynamically favored. ${ }^{23}$ DFT-vdW results are compared to values deduced from the experimental standard enthalpies (per oxygen atom) of oxide formation $\Delta_{f} H^{0}(298.15 \mathrm{~K}) .{ }^{32,33}$

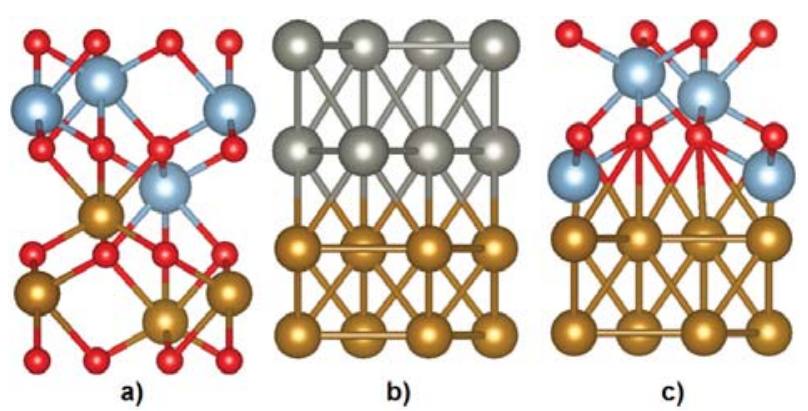

Figure 2: Schematic representation of a) oxide $($ oxide, b) metal $\mid$ metal, and c) oxide $\mid$ metal interfaces. Oxygen atoms are represented by small red balls, cations and metal atoms by large blue and golden balls, respectively. ${ }^{34}$ 
in the calculations. All calculations on individual interfaces were performed in a superlattice geometry involving two identical interfaces per periodic unit cell and having the in-plane lattice parameters fixed to the theoretical bulk alumina ones $(a=4.81 \AA)$. Driven by the $\mathrm{Al}_{2} \mathrm{O}_{3}(0001)$ substrate, a corundum structure was also assumed for chromium and iron oxides and three $-\mathrm{M} / 3 \mathrm{O} / \mathrm{M}-(0001)$ tri-layers with a $(1 \times 1)$ in-plane periodicity were used in superlattice calculations. Conversely, the metal components were represented by seven dense atomic layers $[\mathrm{Cr}(110), \mathrm{Fe}(110), \mathrm{Ni}(111)$ and $\mathrm{Zn}(0001)]$, for which the best in-plane commensurability with the oxides was provided by a (distorted) $(\sqrt{3} \times \sqrt{3})$ R30 $0^{\circ}$ unit cell.

All configurations were thoroughly optimized in a series of structural relaxations starting from various interface lattice registries. The lattice parameters in the direction normal to the interface were optimized in order to relax distances between subsequent atomic planes and positions of all atoms were relaxed until residual forces became smaller than $0.01 \mathrm{eV} / \AA$. In all calculations, we employed a $\Gamma$-centered $8 \times 8$ Monkhorst-Pack grid for k-point sampling of the Brillouin zone of the $(1 \times 1)$ surface unit cell of alumina.

The interface energy of an individual $\mathrm{A} \mid \mathrm{B}$ interface was defined as:

$$
\mathrm{E}_{\text {int }}^{\mathrm{A} \mid \mathrm{B}}=\left(\mathrm{E}^{\mathrm{A} \mid \mathrm{B}}-\mathrm{E}_{\mathrm{bulk}}^{\mathrm{A}}-\mathrm{E}_{\text {bulk }}^{\mathrm{B}}\right) / 2 S,
$$

where $\mathrm{E}^{\mathrm{A} \mid \mathrm{B}}$ is the total energy of the $\mathrm{A} \mid \mathrm{B}$ superstructure and $\mathrm{E}_{\text {bulk }}^{\mathrm{A}}$ and $\mathrm{E}_{\text {bulk }}^{\mathrm{B}}$ are the total energies of bulk materials A and B (with the same in-plane lattice parameters as the superstructure). Factor 2 accounts for the two equivalent $\mathrm{A} \mid \mathrm{B}$ interfaces in the periodic unit cell and $\mathrm{S}$ is the interface area. Interface energy of an $\mathrm{A} \mid \mathrm{A}$ interface is hence equal to zero.

The adhesion energy at an individual $\mathrm{A} \mid \mathrm{B}$ interface was estimated by its separation energy:

$$
\mathrm{W}^{\mathrm{A} \mid \mathrm{B}}=\left(\mathrm{E}^{\mathrm{A} \mid \mathrm{B}}-\mathrm{E}_{\text {slab }}^{\mathrm{A}}-\mathrm{E}_{\text {slab }}^{\mathrm{B}}\right) / 2 S,
$$

where $\mathrm{E}^{\mathrm{A} \mid \mathrm{B}}, \mathrm{E}_{\text {slab }}^{\mathrm{A}}$, and $\mathrm{E}_{\text {slab }}^{\mathrm{B}}$ are the total energies of the $\mathrm{A} \mid \mathrm{B}$ superstructure and of its isolated $\mathrm{A}$ and $\mathrm{B}$ parts in contact with vacuum (with the same in-plane lattice parameters as in the 
superstructure). We remind that, since interface and adhesion energies are linked by the relationship $\mathrm{W}^{\mathrm{A} \mid \mathrm{B}}=\sigma^{\mathrm{A}}+\sigma^{\mathrm{B}}-\mathrm{E}_{\text {int }}^{\mathrm{A} \mid \mathrm{B}}$ (with $\sigma^{\mathrm{A}}$ and $\sigma^{\mathrm{B}}$ the surface energies of $\mathrm{A}$ and $\mathrm{B}$ ), $\mathrm{W}^{\mathrm{A} \mid \mathrm{A}}=2 \sigma^{\mathrm{A}}$.

The effect of a systematic increase of interaction strength by dispersion-corrected exchangecorrelation functional on the surface and adhesion energies of some of the materials relevant for the present study has been explicitly estimated in Ref. 22. Here, surfaces energies of metals, alumina, and transition metal oxides are enhanced by about $0.2,0.3$, and $0.4 \mathrm{~J} / \mathrm{m}^{2}$ with respect to the corresponding GGA ${ }^{35,36}$ or GGA+U values, ${ }^{37}$ respectively. Consistently, adhesion energies are also increased with respect to GGA results (e.g., $0.3-0.4 \mathrm{~J} / \mathrm{m}^{2}$ at $\mathrm{Zn} \mid$ alumina and $\mathrm{Cr} \mid$ alumina $\left.^{22}\right)$.

The consequences of the lattice distortion imposed in the calculations can be estimated by comparing surface and adhesion energies obtained with the interface structure matching that of alumina or corresponding to a structural average of the two materials. For example, in the case of $\mathrm{Al}_{2} \mathrm{O}_{3} \mid \mathrm{Cr}_{2} \mathrm{O}_{3}$ interface (3\% lattice mismatch), surface and adhesion energies change by less than $0.1-0.2 \mathrm{~J} / \mathrm{m}^{2}$. This difference is somewhat larger $\left(0.2-0.4 \mathrm{~J} / \mathrm{m}^{2}\right)$ in the case of $\mathrm{Al}_{2} \mathrm{O}_{3} / \mathrm{Fe}$ (13\% lattice mismatch). The impact of the uncertainties due to the choice of exchange-correlation functional and of interface models will be discussed in the following sections.

Monte Carlo Metropolis simulations. The MC Metropolis algorithm ${ }^{38}$ was used to generate the thermodynamically most favorable sequences of components in the alumina $\left|\mathrm{X}_{1}\right| \mathrm{X}_{2}\left|\mathrm{X}_{3}\right| \ldots\left|\mathrm{X}_{\mathrm{N}}\right|$ zin superstructure. At each $\mathrm{MC}$ step, two randomly chosen components $\mathrm{X}_{\mathrm{i}}$ and $\mathrm{X}_{\mathrm{j}}$ were tentatively exchanged and the new configuration was accepted with probability $p=\min \left[1, \exp \left(-\Delta \mathrm{E} / \mathrm{k}_{\mathrm{B}} \mathrm{T}\right)\right]$, where $\mathrm{k}_{\mathrm{B}}$ is the Boltzmann constant and $\mathrm{T}$ is the temperature. $\Delta \mathrm{E}$ represents the change of the total formation energy $\mathrm{E}=\mathrm{E}_{\text {int }}^{\text {alumina } \mid \mathrm{X}_{1}}+\mathrm{E}_{\text {int }}^{\mathrm{X}_{1} \mid \mathrm{X}_{2}}+\ldots+\mathrm{E}_{\mathrm{int}}^{\mathrm{X}_{\mathrm{N}} \mid \mathrm{zinc}}$ induced by the exchange. In the present simulations, we have used $\mathrm{T}=1500 \mathrm{~K}\left(\mathrm{k}_{\mathrm{B}} \mathrm{T} / \mathrm{S} \sim 0.1 \mathrm{~J} / \mathrm{m}^{2}\right)$ and $20 \times 10^{6} \mathrm{MC}$ steps and the results were averaged after a system equilibration of $10^{6}$ steps. 
As to represent a realistic composition profile of the buffer and to enable mixing and/or separation of each of its components, the latter were represented by several replicas each and the position of each replica was independently optimized. Typically, the stainless steel buffer was represented by $12 \mathrm{Fe}, 2 \mathrm{Cr}$, and $2 \mathrm{Ni}$ replicas, which corresponds to its typical composition $75 \% \mathrm{Fe}, 12.5 \% \mathrm{Cr}$, and $12.5 \% \mathrm{Ni}$. Each oxide component was represented by two replicas. The possible diffusion of $\mathrm{Zn}$ into the buffer was accounted for by the addition of one replica of $\mathrm{Zn}$. The convergence of the results was tested by simulations in which the number of replicas of each component was doubled.

\section{Results: Energetics of individual interfaces}

In this section, we report the results on interface and adhesion energies at the individual interfaces, obtained from ab initio calculations. All relevant oxide|oxide interfaces $\left(\mathrm{Al}_{2} \mathrm{O}_{3}\right.$, $\mathrm{Cr}_{2} \mathrm{O}_{3}$, and $\left.\mathrm{Fe}_{2} \mathrm{O}_{3}\right)$, metal|metal (Cr, Fe, Ni and $\mathrm{Zn}$ ) and metal|oxide interfaces are considered.

Table 1: Interface $E_{\text {int }}\left(\mathrm{J} / \mathrm{m}^{2}\right)$ and adhesion $\mathrm{W}\left(\mathrm{J} / \mathrm{m}^{2}\right)$ energies at individual oxide|oxide interfaces.

$\begin{array}{lccc} & \mathrm{Al}_{2} \mathrm{O}_{3} & \mathrm{Cr}_{2} \mathrm{O}_{3} & \mathrm{Fe}_{2} \mathrm{O}_{3} \\ \mathrm{E}_{\text {int }} & & & \\ \mathrm{Al}_{2} \mathrm{O}_{3} & 0.00 & 0.38 & 0.43 \\ \mathrm{Cr}_{2} \mathrm{O}_{3} & 0.38 & 0.00 & 0.17 \\ \mathrm{Fe}_{2} \mathrm{O}_{3} & 0.43 & 0.17 & 0.00 \\ & & & \\ \mathrm{~W} & & & \\ \mathrm{Al}_{2} \mathrm{O}_{3} & 3.88 & 3.57 & 3.02 \\ \mathrm{Cr}_{2} \mathrm{O}_{3} & 3.57 & 4.02 & 3.35 \\ \mathrm{Fe}_{2} \mathrm{O}_{3} & 3.02 & 3.35 & 3.04\end{array}$

Oxide|oxide interfaces. Interface energies of all oxide|oxide interfaces are found to be small and positive $\left(<0.5 \mathrm{~J} / \mathrm{m}^{2}\right)$, Tab.1. This is consistent with the fact that no change in the number of metal-oxygen bonds or in the cation oxidation state occurs when the 
interface is formed from the two bulk materials. Interface energies of $\mathrm{Al}_{2} \mathrm{O}_{3} \mid \mathrm{M}_{2} \mathrm{O}_{3}(\mathrm{M}=\mathrm{Cr}$ and $\mathrm{Fe}$ ) are the largest due to a larger structural mismatch and to a noticeable difference in the cation-oxygen bond iono-covalent character between $\mathrm{Al}_{2} \mathrm{O}_{3}$ and the transition metal oxides. Conversely, the interface energy of the $\mathrm{Cr}_{2} \mathrm{O}_{3} \mid \mathrm{Fe}_{2} \mathrm{O}_{3}$ interface is the smallest owing to the structural and bonding similarities of the two oxides. Since the interface energies are small, the adhesion energies roughly scale with the sum of the surface energies of the two components: $\mathrm{W}^{\mathrm{A} \mid \mathrm{B}} \sim \sigma^{\mathrm{A}}+\sigma^{\mathrm{B}}$. As a consequence, we find a strong adhesion $\left(3-4 \mathrm{~J} / \mathrm{m}^{2}\right)$ at all oxide|oxide interfaces upon consideration, Tab. 1.

Table 2: Interface $E_{\text {int }}\left(\mathrm{J} / \mathrm{m}^{2}\right)$ and adhesion $\mathrm{W}\left(\mathrm{J} / \mathrm{m}^{2}\right)$ energies at individual metal $\mid$ metal interfaces.

$\begin{array}{lcccc} & \mathrm{Cr} & \mathrm{Fe} & \mathrm{Ni} & \mathrm{Zn} \\ \mathrm{E}_{\text {int }} & & & & \\ \mathrm{Cr} & 0.00 & -0.50 & -0.36 & -0.51 \\ \mathrm{Fe} & -0.50 & 0.00 & -0.51 & -0.30 \\ \mathrm{Ni} & -0.36 & -0.51 & 0.00 & -0.73 \\ \mathrm{Zn} & -0.51 & -0.30 & -0.73 & 0.00 \\ & & & & \\ \mathrm{~W} & & & & \\ \mathrm{Cr} & 4.14 & 4.69 & 4.44 & 3.11 \\ \mathrm{Fe} & 4.69 & 4.24 & 4.64 & 2.95 \\ \mathrm{Ni} & 4.44 & 4.64 & 4.02 & 3.27 \\ \mathrm{Zn} & 3.11 & 2.95 & 3.27 & 1.06\end{array}$

Metal $\mid$ metal interfaces. Metal $\mid$ metal interfaces are also characterized by relatively small interface energies $\left(\left|E_{\text {int }}\right| \leq 0.7 \mathrm{~J} / \mathrm{m}^{2}\right)$, Tab. 2, which is consistent with the absence of substantial structural (bond number) or chemical (oxidation state, bond iono-covalent character) changes upon interface formation. However, contrary to the case of oxide |oxide interfaces, negative values of $E_{i n t}$ are found, which indicate a tendency for alloying, especially well pronounced at the Ni|Zn interface. Similarly to the case of oxide|oxide interfaces, the adhesion energies roughly scale with the sum of the surface energies of the two components, resulting in a strong adhesion (3-4 J/m $\left.\mathrm{m}^{2}\right)$ at nearly all metal|metal interfaces, Tab. 2. The only exception is the $\mathrm{Zn} \mid \mathrm{Zn}$ interface, with a particularly small adhesion energy $\left(\sim 1 \mathrm{~J} / \mathrm{m}^{2}\right)$, which 
originates from the small surface energy of Zn. Representative for the strength of the zinc film itself, we will refer to this value in the following discussion.

Table 3: Interface energies $E_{\text {int }}\left(\mathrm{J} / \mathrm{m}^{2}\right)$ and adhesion energies $\mathrm{W}\left(\mathrm{J} / \mathrm{m}^{2}\right)$ at individual oxide $\mid$ metal interfaces.

$\begin{array}{lcccc} & \mathrm{Cr} & \mathrm{Fe} & \mathrm{Ni} & \mathrm{Zn} \\ \mathrm{E}_{\text {int }} & & & & \\ \mathrm{Al}_{2} \mathrm{O}_{3} & 2.01 & 2.16 & 2.10 & 1.82 \\ \mathrm{Cr}_{2} \mathrm{O}_{3} & 1.72 & 1.13 & 1.42 & 1.52 \\ \mathrm{Fe}_{2} \mathrm{O}_{3} & -1.21 & 0.15 & 0.51 & 0.79 \\ & & & & \\ \mathrm{~W} & & & & \\ \mathrm{Al}_{2} \mathrm{O}_{3} & 2.00 & 1.90 & 1.85 & 0.65 \\ \mathrm{Cr}_{2} \mathrm{O}_{3} & 2.36 & 3.00 & 2.60 & 1.02 \\ \mathrm{Fe}_{2} \mathrm{O}_{3} & 4.79 & 3.48 & 3.01 & 1.25\end{array}$

Oxide $\mid$ metal interfaces. The energetics of oxide|metal interfaces qualitatively differs from that of oxide $\mid$ oxide and metal $\mid$ metal ones. In most cases, $\left|E_{\text {int }}\right|$ values are large (1$2 \mathrm{~J} / \mathrm{m}^{2}$ ) due to a change of both the number/type of bonds and of the cation oxidation state upon interface formation. Indeed, the formation of a $\mathrm{M}_{2} \mathrm{O}_{3} \mid \mathrm{M}^{\prime}$ interface involves breaking $\mathrm{M}-\mathrm{O}$ bonds and forming $\mathrm{M}^{\prime}-\mathrm{O}$ ones. The trend for a progressive increase of $\mathrm{E}_{\text {int }}$ along each line and its decrease along each column in Tab. 3 are well accounted for by the changes of the enthalpies of metal oxidation, Figure 1. In particular, the largest positive $\mathrm{E}_{\text {int }}$ are obtained when strong bonds $(\mathrm{Al}-\mathrm{O})$ are replaced by weaker ones $(\mathrm{M}-\mathrm{O})$. Conversely, the most negative value corresponds to a replacement of relatively weak $(\mathrm{Fe}-\mathrm{O})$ bonds by stronger $(\mathrm{Cr}-\mathrm{O})$ ones, actually highlighting the instability of the $\mathrm{Fe}_{2} \mathrm{O}_{3} \mid \mathrm{Cr}$ interface with respect to the $\mathrm{Cr}_{2} \mathrm{O}_{3} \mid \mathrm{Fe}$ one. Finally, a close to zero $\mathrm{E}_{\text {int }}$ value is found at the $\mathrm{Fe}_{2} \mathrm{O}_{3} \mid \mathrm{Fe}$ interface where no change of the number/type of bonds or cation oxidation state takes place.

Adhesion energies at oxide|metal interfaces are moderate to large $\left(2-5 \mathrm{~J} / \mathrm{m}^{2}\right)$, except in the cases of $\mathrm{M}_{2} \mathrm{O}_{3} \mid \mathrm{Zn}$, where large interface energies and small zinc surface energy lead to a weak adhesion, of the order of $1 \mathrm{~J} / \mathrm{m}^{2}$ only. In particular, zinc adhesion at the alumina (0001) surface is very weak $\left(0.65 \mathrm{~J} / \mathrm{m}^{2}\right)$ and representative for the observed bad adhesion of 
anti-corrosive zinc coatings at the surfaces of advanced high strength steels. We will refer to this value in the following discussion.

We stress that the discussed qualitative differences in interface energetics of oxide/oxide, metal/metal, and oxide/metal interfaces reflect the very different nature of these objects and go well beyond effects due to either a choice of exchange-correlation functional or an approximate treatment of interface strain effects.

To summarize, ab initio results allow drawing an early picture of the expected behavior of the various components of a multi-component buffer. On the one hand, the negative $\mathrm{E}_{\text {int }}$ obtained at metal $\mid$ metal interfaces suggest a systematic tendency for alloying of the metallic components. On the other hand, positive values for most oxide|oxide and oxide|metal interfaces will lead to a reduction of the number of such interfaces and will drive a separation of the oxide and metal components. As far as the strength of individual interfaces is concerned, adhesion energies obtained for oxide |oxide and for most metal $\mid$ metal interfaces (except Zn $\mid \mathrm{Zn}$ ) are systematically large. Oxide|metal interfaces (except oxide $\mid \mathrm{Zn}$ ) are also characterized by relatively large adhesion energies, especially in the case of $\mathrm{Fe}_{2} \mathrm{O}_{3} \mid$ metal. Since the overall junction strength is determined by the weakest interface formed in the buffer, these results suggest that any attempt to strengthen the interface has to aim at eliminating all oxide $\mid$ zinc interfaces.

\section{Results: Equilibrium structure of multi-component buffers}

In this section, we determine the component sequence in a multi-component buffer at thermodynamic equilibrium, by MC optimization. We consider a typical stainless steel buffer of average composition $75 \% \mathrm{Fe}, 12.5 \% \mathrm{Cr}$, and $12.5 \% \mathrm{Ni}$, under three different oxidizing conditions, Figure 1: a) oxygen-lean conditions under which the buffer remains metallic, b) oxygen-moderate conditions under which $\mathrm{Cr}$ is partially oxidized, and c) oxygen-rich conditions under which the $\mathrm{Cr}$ component is fully oxidized and Fe is partially oxidized. The 
possibility of zinc diffusion from the coating towards the buffer is accounted for by adding a Zn component in the buffer. In all cases, the spatial distribution of the relevant metal and oxide components and the probability of formation of individual interfaces are determined and the weakest adhesive interface is identified. We first consider a self-standing stainless steel buffer, which is subsequently inserted at the alumina|zinc interface.

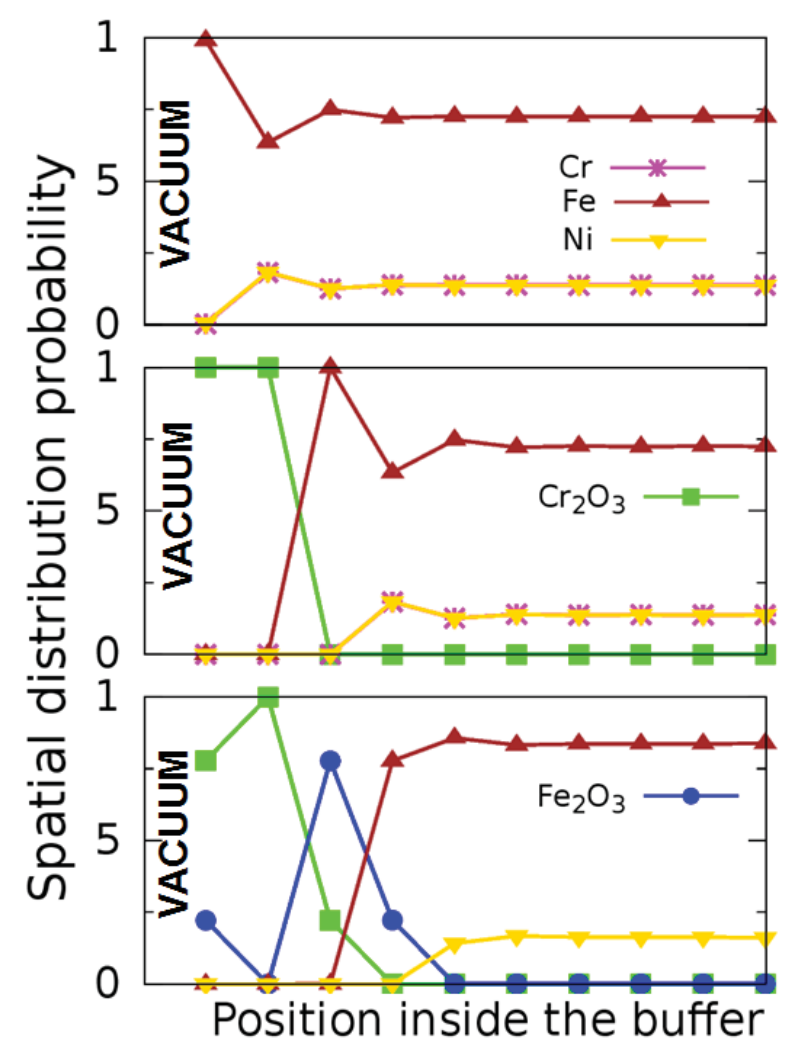

Figure 3: Spatial distribution of components in a self-standing stainless steel buffer in oxygenlean (top), -moderate (middle), and -rich (bottom) environments.

Self-standing stainless steel buffer. Figure 3 displays the spatial distribution of components in a self-standing stainless steel buffer under the three considered oxidizing conditions. In all cases, in the buffer center (right-hand side of the diagrams), the metallic components (Fe, Cr, and $\mathrm{Ni}$ ) form an alloy with a composition close to that expected from the average buffer one.

In an oxygen-lean environment (buffer composed only of $\mathrm{Fe}, \mathrm{Cr}$, and Ni), Fig. 3 (top), 
the surface gets enriched in Fe, although $\mathrm{Cr}$ and $\mathrm{Ni}$ have lower surface energies. This comes from the fact that these two metals have a strong preference to alloy with Fe, Tab. 2, which makes them more stable in the buffer core, as long as Fe is largely in excess.

In an oxygen-moderate environment (buffer composed of $\mathrm{Fe}, \mathrm{Cr}, \mathrm{Ni}$, and $\mathrm{Cr}_{2} \mathrm{O}_{3}$ ), Fig. 3 (middle), the $\mathrm{Cr}_{2} \mathrm{O}_{3}$ component segregates to the surface, thus limiting the number of chromia|metal interfaces, as expected from their relatively large $\mathrm{E}_{\text {int }}$, Tab. 3. This separation corresponds to the known sacrificial Cr oxidation which prevents oxygen diffusion into the stainless steel and thus protects it from further corrosion. Below the superfical chromia film, the buffer is enriched in Fe which ensures a good adhesion to the protective oxide film.

In an oxygen-rich environment (buffer composed of $\mathrm{Fe}, \mathrm{Ni}, \mathrm{Cr}_{2} \mathrm{O}_{3}$, and $\mathrm{Fe}_{2} \mathrm{O}_{3}$ ), Fig. 3 (bottom), the situation remains similar, but since most $\mathrm{Fe}_{2} \mathrm{O}_{3}$ segregates at the chromia|Fe interface the oxide|buffer interface switches from $\mathrm{Cr}_{2} \mathrm{O}_{3} \mid \mathrm{Fe}$ to $\mathrm{Fe}_{2} \mathrm{O}_{3} \mid \mathrm{Fe}$, which strengthens the entire system even more $\left[\mathrm{W}\left(\mathrm{Cr}_{2} \mathrm{O}_{3} \mid \mathrm{Fe}\right)=3.0 \mathrm{~J} / \mathrm{m}^{2}\right)$ and $\left.\mathrm{W}\left(\mathrm{Fe}_{2} \mathrm{O}_{3} \mid \mathrm{Fe}\right)=3.5 \mathrm{~J} / \mathrm{m}^{2}\right]$. We note that the $\mathrm{Fe}_{2} \mathrm{O}_{3}$ does not significantly segregate to the surface despite the fact that its surface energy is smaller than that of $\mathrm{Cr}_{2} \mathrm{O}_{3}$, but tends to form a strong $\mathrm{Fe}_{2} \mathrm{O}_{3} \mid \mathrm{Fe}$ interface.

Stainless steel buffer at the alumina|zinc interface. The spatial distribution of components in a stainless steel buffer introduced at the alumina|zinc interface under the same three oxidizing conditions is shown in Fig. 4. With respect to the previous description, the main modifications take place at the interfaces with $\mathrm{Zn}$ and alumina, while the distribution of components in the core of the buffer remains nearly unchanged.

Under oxygen-lean conditions, Fig. 4 (top), a segregation of Fe takes place at the interface with $\mathrm{Al}_{2} \mathrm{O}_{3}$, while $\mathrm{Fe}$ and $\mathrm{Ni}$ move to the interface with $\mathrm{Zn}$. The resulting component sequence is $\mathrm{Al}_{2} \mathrm{O}_{3}|\mathrm{Fe}| \mathrm{Fe}, \mathrm{Cr}, \mathrm{Ni}, \mathrm{Zn}|\mathrm{Fe}, \mathrm{Ni}| \mathrm{Zn}$. Driven by its excess in the buffer, Fe segregates at the contact with $\mathrm{Al}_{2} \mathrm{O}_{3}$, as it does at the surface of a self-standing buffer. At the $\mathrm{Zn}$ interface, the enrichment in $\mathrm{Ni}$ is due to a favorable alloying thermodynamics between these two metals. Thanks to the presence of the stainless steel buffer, Zn avoids a direct contact 


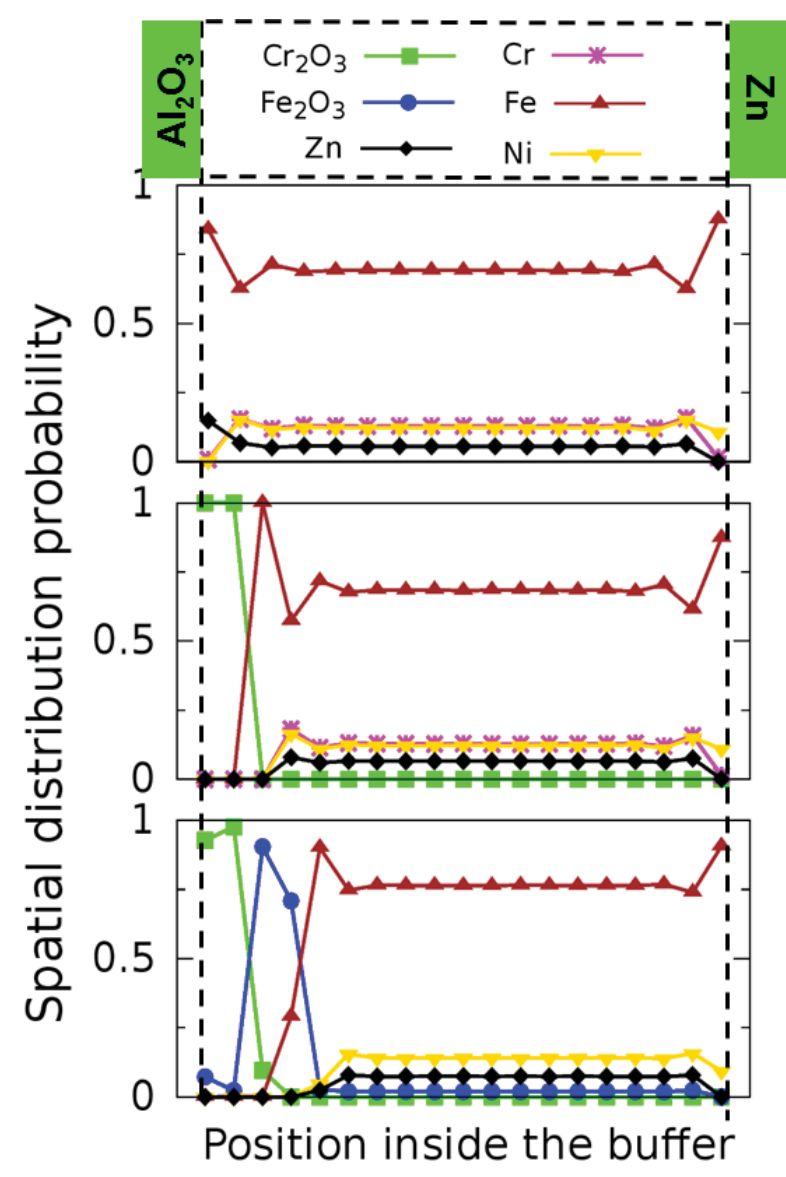

Figure 4: Same as Figure 3 for a buffer sandwiched between alumina and zinc. 
with the $\mathrm{Al}_{2} \mathrm{O}_{3}$ substrate, which strengthens the system. In order to quantify the effect, the distribution of the individual interfaces formed within the buffer, ordered by their adhesion energy, is given in Fig. 5 (pink line). The least adhesive interface under oxygen-lean environment is the $\mathrm{Al}_{2} \mathrm{O}_{3} \mid \mathrm{Fe}$ one, with an adhesion energy of about $1.9 \mathrm{~J} / \mathrm{m}^{2}$, which is much larger than that of $\mathrm{Al}_{2} \mathrm{O}_{3} \mid \mathrm{Zn}\left(0.65 \mathrm{~J} / \mathrm{m}^{2}\right)$. It is also larger than the adhesion at the $\mathrm{Zn} \mid \mathrm{Zn}$ interface $\left(1.06 \mathrm{~J} / \mathrm{m}^{2}\right)$, which is representative for the strength of the anti-corrosive coating itself.

Under oxygen-moderate conditions, Fig. 4 (middle), $\mathrm{Cr}_{2} \mathrm{O}_{3}$ tends to segregate at the interface with alumina, without a noticeable impact on the remaining buffer sequence $\mathrm{Al}_{2} \mathrm{O}_{3}\left|\mathrm{Cr}_{2} \mathrm{O}_{3}\right| \mathrm{Fe} \mid \mathrm{Fe}, \mathrm{Cr}, \mathrm{N}$ The weakest interfaces become the $\mathrm{Cr}_{2} \mathrm{O}_{3} \mid \mathrm{Fe}$ and $\mathrm{Fe} \mid \mathrm{Zn}$ ones, with an adhesion energy of about $3.0 \mathrm{~J} / \mathrm{m}^{2}$, Fig. 5 (green line), larger than that obtained for the fully metallic buffer. Further oxidation of the stainless buffer, Fig. 4 (bottom), adds the $\mathrm{Fe}_{2} \mathrm{O}_{3}$ component, which is found to mainly segregate at the oxide|metal interface. The buffer sequence thus becomes $\mathrm{Al}_{2} \mathrm{O}_{3}\left|\mathrm{Cr}_{2} \mathrm{O}_{3}\right| \mathrm{Fe}_{2} \mathrm{O}_{3}|\mathrm{Fe}| \mathrm{Fe}, \mathrm{Fe}_{2} \mathrm{O}_{3}, \mathrm{Cr}, \mathrm{Ni}, \mathrm{Zn}|\mathrm{Fe}, \mathrm{Ni}| \mathrm{Zn}$. Owing to a good adhesion at the $\mathrm{Fe}_{2} \mathrm{O}_{3} \mid \mathrm{Fe}$ contact, the weakest interface is the $\mathrm{Fe} \mid \mathrm{Zn}$ one, with an adhesion energy close to $3.0 \mathrm{~J} / \mathrm{m}^{2}$, Fig.5 (blue line). Under such oxygen-rich conditions, some of the iron oxide also appears in the central part of the buffer, due to the low $\mathrm{Fe}_{2} \mathrm{O}_{3} \mid$ Fe interface energy.

Under oxidizing conditions, the separation of oxide and metal components in the buffer is driven by small interface energies of the oxide|oxide interfaces and negative $\mathrm{E}_{\text {int }}$ of the metal|metal ones, as compared to large positive $\mathrm{E}_{\text {int }}$ found for metal|oxide contacts. Interestingly, the segregation of Fe to the metal/oxide interfaces whether the interface energetics is favorable $\left(\mathrm{Fe}_{2} \mathrm{O}_{3} \mid \mathrm{Fe}\right.$ and $\left.\mathrm{Cr}_{2} \mathrm{O}_{3} \mid \mathrm{Fe}\right)$ or not $\left(\mathrm{Al}_{2} \mathrm{O}_{3} \mid \mathrm{Fe}\right)$ is mainly due to iron excess in the stainless steel buffer.

Accordingly, let us stress that the buffer characteristics are relatively insensitive to the precise values of $\mathrm{E}_{\mathrm{int}}$ and $\mathrm{W}$. On the one hand, the separation of oxide and metal components is driven by the fact that most $\mathrm{E}_{\text {int }}$ (oxide|metal) are much larger than oxide|oxide and metal|metal interface energies. Beyond the computational accuracy, this difference of inter- 
face energies is due to the very different nature of metal $\mid$ metal, oxide $\mid$ oxide, and metal $\mid$ oxide interfaces. On the other hand, Fe excess in the stainless steel buffer rather than precise interface energy values is responsible for the Fe segregation at metal|oxide interfaces and for the suppression of weakly adhesive zinc|oxide contacts. Thus, our conclusions should not be altered by either a different choice of the exchange-correlation functional, or by refinements in the structural description of the interfaces.

In summary, our results show that stainless steel buffers, when fully metallic, substantially improve the strength of alumina|zinc junctions, by replacing this particularly weak oxide|metal interface by a much more adhesive alumina|iron one. Interestingly, a (partial) oxidation of the buffer, associated with the formation of chromium and/or iron oxides, does not degrade the good buffer performance. This is assigned to a clear separation of all oxide and metallic components (i.e., to the reduction of the number of thermodynamically less stable oxide/metal interfaces), and to the segregation of Fe towards the oxide|metal interface (i.e., suppression of any $\mathrm{Zn} \mid$ oxide interface). When increasing the oxidizing conditions, these effects move the weakest individual interface from alumina|iron to chromia|iron and (metal $\mid$ metal) Fe $\mid \mathrm{Zn}$ interfaces.

\section{Discussion}

We have developed a simplified model which accounts for the interactions which take place when a multi-component stainless steel buffer is introduced between an alumina substrate and a zinc coating. The comparison with the case of a single-component buffer which follows shows that the adhesion performance under realistic oxidizing conditions is greatly improved. We will then analyze how these performances are modified by either atom inter-diffusion at the interface or by a change of the $\mathrm{Cr} / \mathrm{Fe}$ or $\mathrm{Ni} / \mathrm{Fe}$ concentration ratios in the stainless steel.

Comparison between single- and multi-component buffers. We have shown in the past that, while single-component metallic buffers improve substantially the adhesion at an 


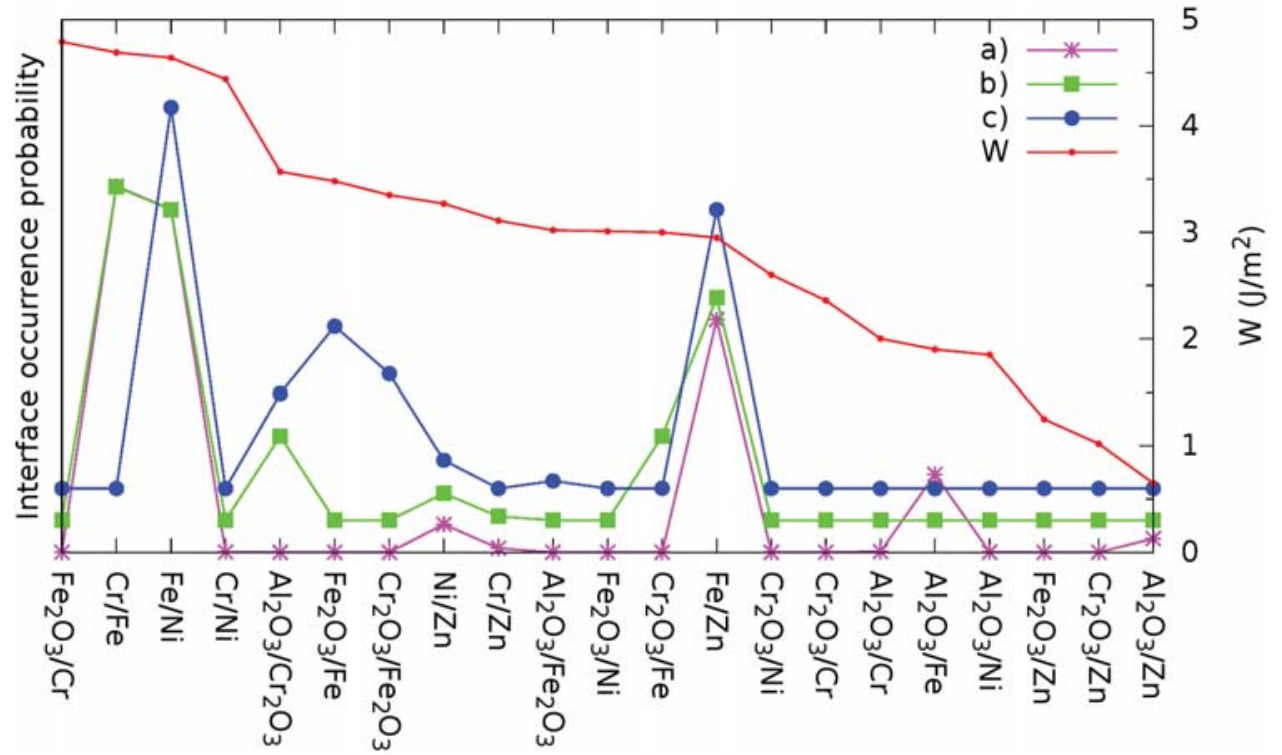

Figure 5: Distribution of individual interfaces in stainless steel buffers with respect to their adhesion energy in the three oxidizing environments: oxygen-lean (a), oxygen-moderate (b) and oxygen-rich (c), and their corresponding adhesion energies (red line, right-hand side scale). For clarity, (b) and (c) diagrams have been vertically shifted with respect to (a).

alumina|zinc interface, their oxidation has a strong detrimental effect due to the weakness of either alumina|oxide or oxide|zinc interfaces. ${ }^{23}$ The present results show that, at variance, multi-component buffers are much less subject to such deficiencies, thanks to their selective oxidation and to a favorable component separation. On the one hand, any weak oxide /zinc interface is efficiently replaced by much more adhesive oxide|Fe ones, owing to a strong thermodynamic tendency for iron segregation at the oxide|metal interfaces. On the other hand, the presence of transition metal oxides which result from the partial buffer oxidation and their segregation towards the alumina substrate efficiently suppress the somewhat weaker alumina|metal interfaces. As a consequence, with respect to a well-performing purely metallic buffer (oxygen-lean conditions), the partial buffer oxidation (oxygen-moderate and oxygen-rich conditions), which is unavoidable under realistic oxidizing environments, tends to additionally improve the performance of a multi-component buffer, while it drastically reduces that of a single-component one. 
Figure 6: Initial $(i)$ and final $(f)$ configurations representing an cationic exchange at oxide oxide (a) and oxide $\mid$ metal (b) interfaces.

Inter-diffusion at oxide|oxide and oxide|metal interfaces. At temperatures typical for the galvanic fabrication of anti-corrosive coatings, an inter-diffusion of atoms at the interfaces may occur. Such possibility was neglected in our ab initio simulations of individual interfaces, Sec. 3, but metal mixing was taken into account in an effective way by the Monte Carlo procedure.

We now mimic inter-diffusion effects by exchanging interfacial cations at oxide|oxide and oxide|metal interfaces, Fig. 6. With the help of DFT calculations, we estimate the associated modifications of interface and adhesion energies. We have verified that in all cases the exchange of interface ions is more favorable than that of bulk ones, which makes it the most likely to occur at finite temperatures. The results are summarized in Tab. 4.

The changes of interface energy $\Delta \mathrm{E}_{\text {int }}$ due to a cationic exchange at oxide |oxide interfaces are relatively small, suggesting that such exchanges may occur under realistic conditions. The small values of $\Delta \mathrm{E}_{\mathrm{int}}$ are assigned to the fact that the exchanges preserve the cation oxidation state as well as the number and type of metal-oxygen bonds. Most importantly, the ionic exchange does not substantially downgrade the interface adhesion at the $\mathrm{Cr}_{2} \mathrm{O}_{3} \mid \mathrm{Fe}_{2} \mathrm{O}_{3}$ interface, while it noticeably increases it at the $\mathrm{Al}_{2} \mathrm{O}_{3} \mid \mathrm{Cr}_{2} \mathrm{O}_{3}$ and $\mathrm{Al}_{2} \mathrm{O}_{3} \mid \mathrm{Fe}_{2} \mathrm{O}_{3}$ interfaces. As a whole, adhesion energies remain large at all oxide|oxide interfaces under consideration.

In the case of alumina|metal interfaces, a cationic exchange systematically provokes an increase of interface energy, which becomes more and more important along the series $\mathrm{M}=$ $\mathrm{Cr}, \mathrm{Fe}$, and Ni. The explanatory argument is in line with that already developed for interface energies, Sec. 3. Indeed, in the present case, strong Al-O bonds connecting the terminal 
Table 4: Change of interface $\Delta \mathrm{E}_{\text {int }}\left(\mathrm{J} / \mathrm{m}^{2}\right)$ and adhesion $\Delta \mathrm{W}\left(\mathrm{J} / \mathrm{m}^{2}\right)$ energies due to a cationic exchange at oxide $\mid$ oxide and oxide $\mid$ metal interfaces, and resulting adhesion $W^{\prime}$ and interface $E_{\text {int }}^{\prime}$ energies $\left(\mathrm{J} / \mathrm{m}^{2}\right)$.

$\begin{array}{lcccc}\text { Interface } & \Delta E_{\text {int }} & \Delta W & E_{\text {int }}^{\prime} & W^{\prime} \\ \mathrm{Al}_{2} \mathrm{O}_{3} \mid \mathrm{Cr}_{2} \mathrm{O}_{3} & 0.01 & 0.42 & 0.39 & 3.99 \\ \mathrm{Al}_{2} \mathrm{O}_{3} \mid \mathrm{Fe}_{2} \mathrm{O}_{3} & 0.27 & 0.90 & 0.70 & 3.92 \\ \mathrm{Cr}_{2} \mathrm{O}_{3} \mid \mathrm{Fe}_{2} \mathrm{O}_{3} & 0.32 & -0.16 & 0.49 & 3.19 \\ & & & & \\ \mathrm{Al}_{2} \mathrm{O}_{3} \mid \mathrm{Cr} & 0.84 & 0.52 & 2.85 & 2.52 \\ \mathrm{Al}_{2} \mathrm{O}_{3} \mid \mathrm{Fe} & 1.43 & 0.88 & 3.59 & 2.78 \\ \mathrm{Al}_{2} \mathrm{O}_{3} \mid \mathrm{Ni} & 1.81 & 1.91 & 3.91 & 3.76 \\ \mathrm{Cr}_{2} \mathrm{O}_{3} \mid \mathrm{Fe} & 0.18 & 0.65 & 1.31 & 3.65 \\ \mathrm{Cr}_{2} \mathrm{O}_{3} \mid \mathrm{Ni} & 0.89 & 0.71 & 2.31 & 3.31 \\ \mathrm{Fe}_{2} \mathrm{O}_{3} \mid \mathrm{Cr} & -0.49 & -0.58 & -1.70 & 4.21 \\ \mathrm{Fe}_{2} \mathrm{O}_{3} \mid \mathrm{Ni} & 0.30 & -0.03 & 0.81 & 2.98\end{array}$

alumina cation are replaced by weaker bonds, the strength of which decreases progressively along the series. While this unfavorable energetics suggests that such ionic exchanges will be thermodynamically prohibited under realistic conditions, it is important to point out that, in any case, they would not reduce the interface strength. We find only a small $\Delta \mathrm{W}$ for $\mathrm{Al}_{2} \mathrm{O}_{3} \mid \mathrm{Cr}$ and $\mathrm{Al}_{2} \mathrm{O}_{3} \mid \mathrm{Fe}$, but a substantial increase of adhesion at the $\mathrm{Al}_{2} \mathrm{O}_{3} \mid \mathrm{Ni}$ interface.

The energetics of cationic exchange at transition metal oxide|metal interfaces can be rationalized with the same arguments, but it is associated with systematically smaller $\Delta \mathrm{E}_{\text {int }}$, because the $\mathrm{Cr}-\mathrm{O}$ and Fe-O bonds are weaker than the Al-O ones. In the case of $\mathrm{Cr}_{2} \mathrm{O}_{3} \mid$ metal interfaces, the trend when passing from $\mathrm{Fe}$ to $\mathrm{Ni}$ is the same as before and mixing induces a noticeable increase of adhesion. Small modifications of interface and adhesion energies are obtained at the $\mathrm{Fe}_{2} \mathrm{O}_{3} \mid \mathrm{Ni}$ interface. The peculiarity of the $\mathrm{Fe}_{2} \mathrm{O}_{3} \mid \mathrm{Cr}$ interface is the negative value of $\Delta \mathrm{E}_{\mathrm{int}}$, driven by the instability of this interface, already noted in Sec. 3.

Let us note that if an inter-diffusion occurs at the interfaces, it does not alter the hierarchy of the key interface energies, which is responsible for the separation of metal and oxide components in the buffer. Indeed, interface energies of metal|oxide interfaces remain much 
larger compared to those of oxide|oxide and metal|metal ones. Also, the segregation of iron to the oxide interfaces, which is due principally to its excess in the buffer, should not be affected by cation mixing at the interfaces. Finally, the adhesion energies, even if somewhat modified by the inter-diffusion, remain in all cases much larger than those of the reference $\mathrm{Al}_{2} \mathrm{O}_{3} \mid \mathrm{Zn}$ and $\mathrm{Zn} \mid \mathrm{Zn}$ interfaces.

In summary, cation inter-diffusion at oxide|oxide and at some oxide|metal interfaces may be expected under realistic conditions, but it will not substantially modify the buffer structure and will not degrade the buffer performance.

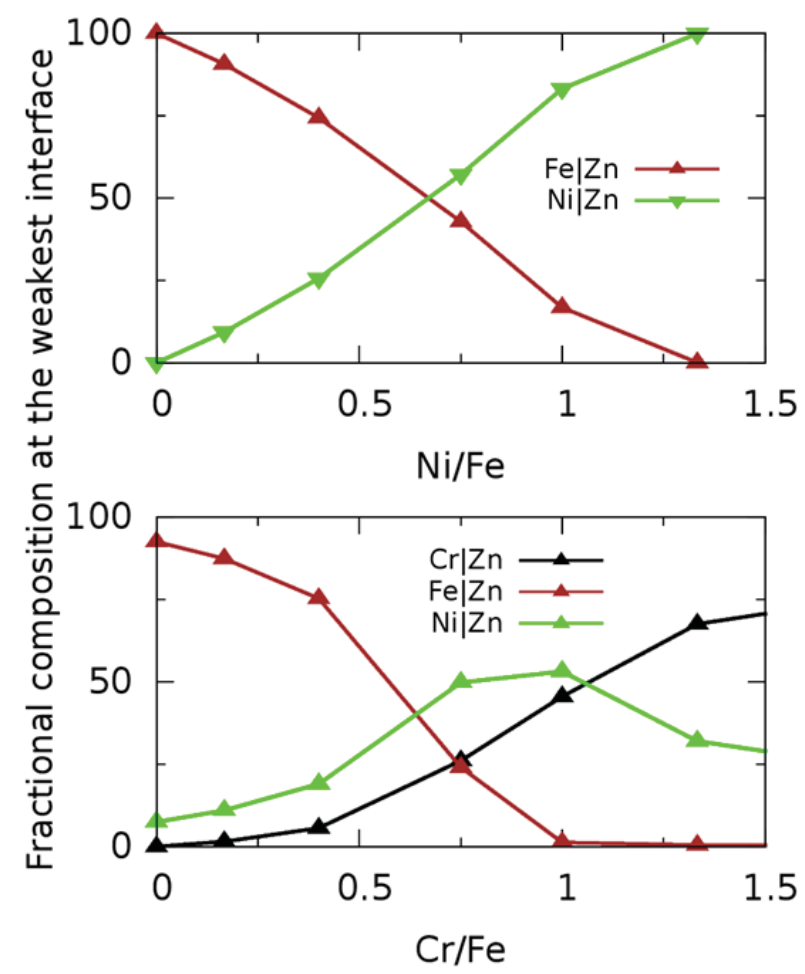

Figure 7: Consequences of a change of buffer composition: (a) proportion of Fe $\mid \mathrm{Zn}$ and Ni|Zn interfaces as a function of the Ni/Fe concentration ratio (oxygen-rich conditions); and (b) proportion of $\mathrm{Cr}|\mathrm{Zn}, \mathrm{Ni}| \mathrm{Zn}$, and $\mathrm{Fe} \mid \mathrm{Zn}$ interfaces as a function of the $\mathrm{Cr} / \mathrm{Fe}$ concentration ratio (oxygen-moderate conditions).

Modification of stainless steel composition. In order to estimate how the performance of the stainless steel buffer may be modified by a change of composition, we now consider a progressive increase of the $\mathrm{Ni} / \mathrm{Fe}$ or $\mathrm{Cr} / \mathrm{Fe}$ concentration ratios. 
Whatever the oxygen conditions, an increase of the Ni content is found to mainly affect the composition of the contact between stainless steel and the zinc coating. At low Ni concentrations the contact is Fe-rich, but Fe becomes progressively replaced by $\mathrm{Ni}$ as the concentration of the latter increases. Such an enrichment of the junction in Ni is thermodynamically favored by the more negative interface energy of the Ni $\mid \mathrm{Zn}$ interface, Tab. 2 . Fig. 7 (top) illustrates this effect in the case of oxygen-rich conditions. Interestingly, since $\mathrm{W}(\mathrm{Ni} \mid \mathrm{Zn})>\mathrm{W}(\mathrm{Fe} \mid \mathrm{Zn})$, Tab. 2, the Ni-enrichment is predicted to additionally improve the adhesion of the zinc coating to the stainless steel buffer.

When changing the $\mathrm{Cr} / \mathrm{Fe}$ concentration ratio, the metal /zinc contact progressively switches from $\mathrm{Fe} \mid \mathrm{Zn}$ to Ni $\mid \mathrm{Zn}$ and $\mathrm{Cr} \mid \mathrm{Zn}$. Fig. 7 (bottom) illustrates this effect in the case of oxygenmoderate conditions. An increase of adhesion of about $0.2-0.3 \mathrm{~J} / \mathrm{m}^{2}$ results, Tab. 2. However, since $\mathrm{W}(\mathrm{Ni} \mid \mathrm{Zn})>\mathrm{W}(\mathrm{Cr} \mid \mathrm{Zn})$, an excessive enrichment in Cr may be not optimal for the buffer performance.

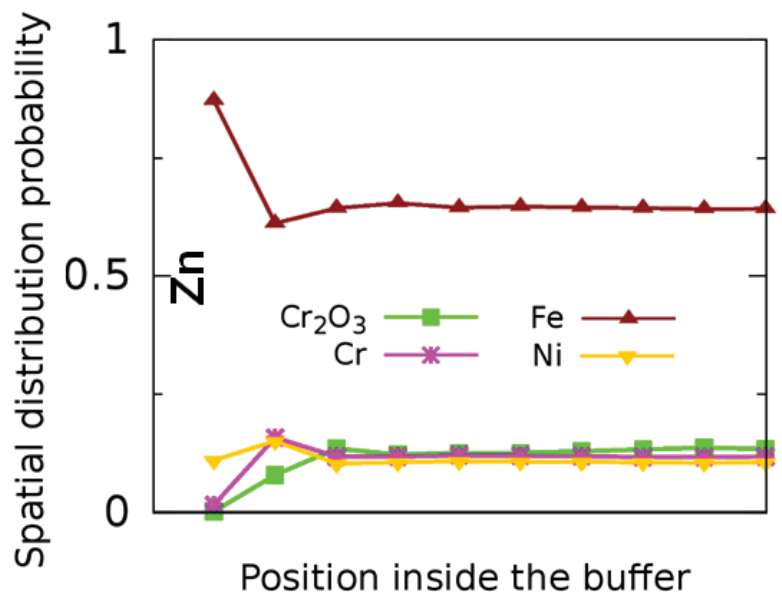

Figure 8: Spatial distribution of components in the stainless steel buffer coated with zinc under oxygen-moderate oxidizing conditions.

Before concluding, it is worth pointing out the two main limitations of our present multicomponent buffer model. On the one hand, we have assumed that the buffer structure may be represented by a stacking of perfect two-dimensional layers. In that way, we transformed the complex three-dimensional buffer structure into a one dimensional stack of components. 
This enabled a significant reduction of the structural complexity and made its optimization computationally treatable. However, in realistic buffers, the various components (e.g., oxides) may form finite size crystallites terminated by facets of different orientations. We note however that, by assuming a layer geometry, our present model tends to over-estimate the detrimental role of the individual weak (and high energy) interfaces. For example, the presence of finite size oxide crystallites embedded in a metal matrix instead of an infinite oxide film is expected to reduce the contribution of weak metal|oxide interfaces to the overall buffer strength.

On the other hand, our study is based on thermodynamic considerations only and the effects driven by the kinetics of ion diffusion are neglected. We note that while the high temperature of the hot-dip galvanization may reduce to some extent the possibility of kinetic hindrance, an extension aiming at an explicit account for ion diffusion is necessary for a sound description of buffer oxidation at ambient temperatures. For example, we find that a strong thermodynamic bias makes chromia segregate at the alumina interface, while, under the actual fabrication conditions, the consecutive deposition of the stainless steel buffer and of the zinc coating may result in the formation of a protective chromia film on the buffer surface before zinc is deposited. To get some insight into its consequences, we have modeled an isolated buffer|zinc system under moderate oxidizing conditions, Fig. 8. We find that, despite the presence of chromia, the contact with the zinc coating is composed uniquely of Fe and Ni, similarly to the results discussed in Sec. 4. The effect is driven by the high $\mathrm{Cr}_{2} \mathrm{O}_{3} \mid \mathrm{Zn}$ interface energy and shows that even if chromia component cannot, for kinetic reasons, entirely segregate at the alumina surface, the Fe and Ni components will efficiently eliminate it from the buffer|zinc junction. 


\section{Conclusions}

In summary, relying on DFT calculations of the energetic characteristics of individual interfaces, we have investigated how the presence of a multi-component buffer impacts the adhesion characteristics at a weak alumina|zinc interface, and we have identified the key factors responsible for its strength. To this goal, interface and adhesion energies of a variety of oxide|oxide, metal|metal, oxide|metal interfaces have been quantified at the $a b$ inito level, and rationalized by analyzing the number and type of interfacial metal-oxygen bonds. Thermodynamic equilibrium structures of multi-components buffers under various oxidizing conditions were then determined by a MC Metropolis approach and their least adhesive parts, relevant for the overall system performance, have been identified.

By considering stainless steel buffers composed of iron alloyed with chromium and nickel, we have broadened our earlier predictions which only applied to single-component buffers. We have shown that adhesion is improved thanks to the iron segregation at the oxide |metal interface, resulting in the replacement of the particularly weak alumina|zinc contact by a much more adhesive alumina|iron one. Even more interestingly, we have demonstrated that the formation of chromium and iron oxides, which may be unavoidable under realistic oxidizing conditions, does not degrade the performances of such multi-component buffers. This effect, which contrasts with the predictions made for single-component buffers, is mainly due to the separation of the oxide and metal components.

Additionally, we have shown that tuning the composition of the stainless steel may further improve its performances. Both an increase of the Ni concentration and a moderate increase of $\mathrm{Cr}$ concentration may be beneficial to adhesion owing to strong Ni-Zn and Cr-Zn interactions. Besides their direct interest for the optimization of industrial adhesive buffers, our results show that an explicit account for selective oxidation and component segregation in a buffer is necessary for a correct estimation of its adhesion characteristics. 


\section{Acknowledgments}

The authors are grateful to Jacques Jupille, Rémi Lazzari, Lucie Gaouyat and Daniel Chaleix for many fruitful discussions, and to IDRIS for a generous allocation of computing time, under Project No. 100170. H.-L. T. Le acknowledges a post-doctoral grant from ArcelorMittal Maizières Research. This work was supported by French state funds managed by the ANR within the Investissements d'Avenir program under reference ANR-11-IDEX-0004-02, and more specifically within the framework of the Cluster of Excellence MATISSE led by Sorbonne Universités.

\section{References}

(1) Marder, A. R. The Metallurgy of Zinc-Coated Steel. Prog. Mater. Sci. 2000, 45, 191271.

(2) Jiang, H.-T.; Ding, W.; Tang, D.; Huang, W. Mechanical Property and Microstructural Characterization of C-Mn-Al-Si Hot Dip Galvanizing TRIP Steel. J. Iron and Steel Research 2012, 19, 29-36.

(3) Nikulin, I.; Sawaguchi, T.; Tsuzaki, K. Effect of Alloying Composition on Low-Cycle Fatigue Properties \& Microstructure of Fe-30Mn-(6-x)Si-xAl TRIP/TWIP Alloys. $M a-$ terials Science and Engineering A 2013, 58\%, 192-200.

(4) Wang, W.; Li, M.; He, C.; Wei, X.; Wang, D.; Dub, H. Experimental Study on High Strain Rate Behavior of High Strength 600-1000 MPa Dual Phase Steels and 1200 MPa Fully Martensitic Steels. Materials and Design 2013, 47, 510-521.

(5) Mertens, A.; Bellhouse, E. M.; McDermid, J. R. Microstructure and Mechanical Properties of a Mixed Si-Al TRIP-Assisted Steel Subjected to Continuous Galvanizing Heat Treatments. Materials Science \& Engineering A 2014, 608, 249-257. 
(6) Drillet, P.; Zermout, Z.; Bouleau, D.; Mataigne, J.-M.; Claessens, S. Selective Oxidation of High Si, Mn and Al Steel Grades During Recrystallization Annealing and Steel/Zn Reactivity. Rev. Metall.-Cah. Inf. Tech. 2004, 10, 831-837.

(7) Guttmann, M. Diffusive Phase Transformations in Hot Dip Galvanizing. Materials Science Forum 1994, 155-156, 527-548.

(8) Triboulet, R.; Perriere, J. Epitaxial Growth of ZnO Films. J. Progress in Crystal Growth and Characterization of Materials 2003, 47, 65-138.

(9) Campbell, C. T. Ultrathin Metal Films and Particles on Oxide Ssurfaces: Structural, Electronic and Chemisorptive Properties. Surface Science Reports 1997, 27, 1-111.

(10) Bogicevic, A.; Jennison, D. R. Variations in the Nature of Metal Adsorption on Ultrathin $\mathrm{Al}_{2} \mathrm{O}_{3}$ Films. Phys. Rev. Lett. 1999, 82, 4050-4053.

(11) Batyrev, I. G.; Alavi, A.; Finnis, M. W. Equilibrium and Adhesion of Nb/sapphire: The Effect of Oxygen Partial Pressure. Phys. Rev. B 2000, 62, 4698-4706.

(12) Siegel, D. J.; Hector, J. L. G.; Adams, J. B. Adhesion, Atomic Structure, and Bonding at the $\mathrm{Al}(111) / \alpha-\mathrm{Al}_{2} \mathrm{O}_{3}(0001)$ Interface: A First Principles Study. Phys. Rev. B 2002, 65,085415 .

(13) Hernandez, N. C.; Graciani, J.; Márquez, A.; Sanz, J. F. Cu, Ag and Au Atoms Deposited on the $\alpha-\mathrm{Al}_{2} \mathrm{O}_{3}(0001)$ Surface: A Comparative Density Functional Study. Surf. Sci. 2005, 575, 189-196.

(14) Briquet, L. G. V.; Catlow, C. R. A.; French, S. A. Comparison of the Adsorption of Ni, Pd, and Pt on the (0001) Surface of $\alpha$-Alumina. J. Phys. Chem. 2008, 112, $18948-18954$.

(15) Melnikov, V. V.; Yeremeev, S. V.; Kulkova, S. E. Theoretical Investigations of 3d-Metal Adsorption on the $\alpha-\mathrm{Al}_{2} \mathrm{O}_{3}(0001)$ Surface. Russ. Phys. J. 2011, 54, 704-712. 
(16) Li, H.; Zhang, W.; Smith, J. R. Advances in ab initio Thermodynamic Studies on Metal/Oxide Interfaces. Phys. Stat. Solidi A. 2011, 208, 1166-1173.

(17) Yoshitake, M.; Yagyu, S.; Chikyow, T. Novel Method for the Prediction of an Interface Bonding Species at Alumina/Metal Interfaces. J. Vac. Sci. Technol. A 2014, 32, 021102-1-8.

(18) Lazzari, R.; Goniakowski, J.; Cabailh, G.; Cavallotti, R.; Trcera, N.; Lagarde, P.; Jupille, J. Surface and Epitaxial Stresses on Supported Metal Clusters. Nano Lett. 2016, 16, 2574-2579.

(19) Rodriguez, J. A.; Kuhn, M.; Hrbek, J. Interaction of Silver, Cesium, and Zinc with Alumina Surfaces: Thermal Desorption and Photoemission StudiesInteraction of Silver, Cesium, and Zinc with Alumina Surfaces: Thermal Desorption and Photoemission Studies. J. Phys. Chem. 1996, 100, 18240-18248.

(20) Lazzari, R.; Jupille, J.; Cavallotti, R.; Simonsen, I. Model-free Unraveling of Supported Nanoparticles Plasmon Resonance Modes. J. Phys. Chem. C 2014, 118, 7032-7048.

(21) Cavallotti, R.; Goniakowski, J.; Lazzari, R.; Jupille, J.; Koltsov, A.; Loison, D. Role of Surface Hydroxyl Groups on Zinc Adsorption Characteristics on $\mathrm{Al}_{2} \mathrm{O}_{3}(0001)$ Surfaces: First-Principles Study. J. Phys. Chem. C 2014, 118, 13578-13589.

(22) Cavallotti, R.; Le, H.-L. T.; Goniakowski, J.; Lazzari, R.; Jupille, J.; Koltsov, A.; Loison, D. New Routes for Improving Adhesion at Metal $/ \mathrm{Al}_{2} \mathrm{O}_{3}(0001)$ Interface. Phys. Chem. Chem. Phys. 2016, 18, 3032-3039.

(23) Le, H.-L. T.; Goniakowski, J.; Noguera, C.; Koltsov, A.; Mataigne, J.-M. FirstPrinciples Study on the Effect of Pure and Oxidized Transition-Metal Buffers on Adhesion at the Alumina/Zinc Interface. J. Phys. Chem. C 2016, 120, 9836-9844. 
(24) Le, H.-L. T.; Lazzari, R.; Goniakowski, J.; Cavallotti, R.; Chenot, S.; Noguera, C.; Jupille, J.; Koltsov, A.; Mataigne, J.-M. Tuning Adhesion at Metal/Oxide Interfaces by Surface Hydroxylation. J. Phys. Chem. C Letters 2017, 121, 11464-11471.

(25) Kresse, G.; Furthmuller, J. Efficient Iterative Schemes for ab initio Total Energy Calculations Using a Plane-Wave Basis Set. Phys. Rev. B 1996, 54, 11169-11186.

(26) Kresse, G.; Hafner, J. Ab initio Molecular Dynamics for Liquid Metals. Phys. Rev. B 1993, $47,558-561$.

(27) Blöchl, P. E. Projector Augmented-Wave Method. Phys. Rev. B 1994, 50, 17953-17979.

(28) Kresse, G.; Joubert, J. From Ultrasoft Pseudopotentials to the Projector AugmentedWave Method. Phys. Rev. B 1999, 59, 1758-1775.

(29) Dion, M.; Rydberg, H.; Schroder, E.; Langreth, D. C.; Lundqvist, B. I. Van der Waals Density Functional for General Geometries. Phys. Rev. Lett. 2004, 92, 246401.

(30) Klimes, J.; Bowler, D. R.; Michaelides, A. Chemical Accuracy for the van der Waals Density Functional. J. Phys.: Cond. Matt. 2010, 22, 022201.

(31) Klimes, J.; Bowler, D. R.; Michaelides, A. Van der Waals Density Functionals Applied to Solids. Phys. Rev. B 2011, 83, 195131.

(32) Chase, M. W. NIST-JAnAF Themochemical Tables, Fourth Edition. J. Phys. Chem. Ref. Data 1998, Monograph 9, 1-1951.

(33) Cox, J. D.; Wagman, D. D.; Medvedev, V. A. CODATA Key Values for Thermodynamics; Hemisphere Publishing Corp.: New York, 1984.

(34) Momma, K.; Izumi, F. VESTA 3 for Three-dimensional Visualization of Crystal, Volumetric and Morphology Data. J. Appl. Crystallogr. 2011, 41, 1272-1276. 
(35) Punkkinen, M. P. J.; Hu, Q.-M.; Kwon, S. K.; Johansson, B.; Kollár, J.; Vitos, L. Surface Properties of 3d Transition Metals. Philosophical Magazine 2011, 91, 36273640.

(36) Ruberto, C.; Yourdshahyan, Y.; Lundqvist, B. I. Surface Properties of Metastable Alumina: A Comparative Study of $\kappa$ - and $\alpha-\mathrm{Al}_{2} \mathrm{O}_{3}$. Phys. Rev. B 2003, 67, 195412.

(37) Rohrbach, A.; Hafner, J.; Kresse, G. Ab initio Study of the (0001) Surfaces of Hematite and Chromia: Influence of Strong Electronic Correlations. Phys. Rev. B 2004, 70, 125426.

(38) Frenkel, D., Smit, B., Eds. Understanding Molecular Simulation: From Algorithms to Applications, 1st ed.; Academic Press, Inc.: Orlando, FL, USA, 1996. 


\section{Graphical TOC Entry}

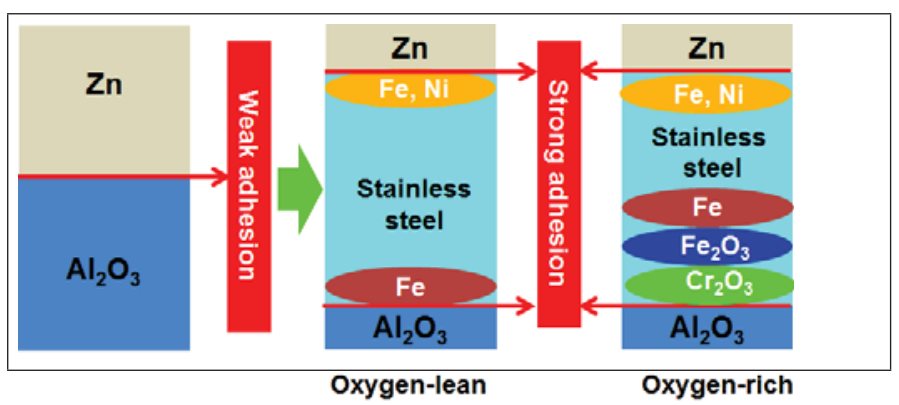

19

20

21 